\title{
Impact of volume expansion on the efficacy and pharmacokinetics of liposome bupivacaine
}

This article was published in the following Dove Press journal:

Local and Regional Anesthesia

7 December 2015

Number of times this article has been viewed

\author{
Admir Hadzic ${ }^{1,2}$ \\ John A Abikhaled ${ }^{3}$ \\ William J Harmon ${ }^{4}$ \\ 'Department of Anesthesiology, \\ The New York School of Regional \\ Anesthesia (NYSORA), New York, NY, \\ USA; ${ }^{2}$ Department of Anesthesiology, \\ Ziekenhouse Oost Limburgh, Genk, \\ Belgium; ${ }^{3}$ Austin Surgeons, Austin, TX, \\ ${ }^{4}$ Urology San Antonio, San Antonio, \\ TX, USA
}

\begin{abstract}
Liposome bupivacaine is a prolonged-release liposomal formulation of bupivacaine indicated for single-dose infiltration into the surgical site to produce postsurgical analgesia of longer duration than traditional local anesthetics. This review summarizes the available data on how volume expansion may impact the analgesic efficacy of liposome bupivacaine. The Phase II and III clinical studies that involved surgical site administration of liposome bupivacaine at various concentrations in different surgical settings revealed no apparent concentration-efficacy relationship. A single-center, prospective study comparing the efficacy of transversus abdominis plane infiltration with liposome bupivacaine administered in a lower $(266 \mathrm{mg} / 40 \mathrm{~mL})$ vs a higher $(266 \mathrm{mg} / 20 \mathrm{~mL})$ dose concentration in subjects undergoing robotic-assisted laparoscopic prostatectomy also reported similar postsurgical pain intensity scores and opioid usage in both treatment groups. The pharmacokinetic profile of liposome bupivacaine following subcutaneous injections in rats was unaltered by differences in drug concentration, dose, or injection volume within the ranges tested. Volume expansion of liposome bupivacaine to a total volume of $300 \mathrm{~mL}$ or less does not appear to impact its clinical efficacy or pharmacokinetic profile, thus allowing flexibility to administer the formulation across a wide range of diluent volumes.
\end{abstract}

Keywords: pain, analgesia, liposome bupivacaine, dose, concentration, dilution

\section{Introduction}

Local anesthetics are frequently used in perioperative multimodal analgesia to enhance analgesia and reduce the need for opioid medications. ${ }^{1}$ In this setting, local anesthetics are most commonly administered to produce regional analgesia (eg, in peripheral nerve blocks or epidural administration) or infiltrated into the surgical site, which provides direct action to peripheral nociceptors in tissues surrounding the surgical area. The utility of traditional local anesthetic formulations is limited by their duration of action. ${ }^{2,3}$

Liposome bupivacaine (bupivacaine liposome injectable suspension, EXPAREL ${ }^{\circledR}$; Pacira Pharmaceuticals, Inc., Parsippany, NJ, USA) is a prolonged-release multivesicular liposomal formulation of bupivacaine indicated for single-dose administration into the surgical site to produce postsurgical analgesia. ${ }^{4}$

The prolonged-release profile of liposome bupivacaine is achieved via the DepoFoam ${ }^{\circledR}$ drug delivery technology, which incorporates multivesicular liposomes comprising phospholipid bilayers that encapsulate aqueous cores containing bupivacaine. ${ }^{5}$ Currently, liposome bupivacaine is available as $266 \mathrm{mg} / 20 \mathrm{~mL}$ vials $(1.33 \%$ [13.3 mg/mL]); $266 \mathrm{mg}$ is the maximum US Food and Drug Administration (FDA)-approved dose. ${ }^{4}$

The doses and concentrations of local anesthetic agents commonly administered intraoperatively into the surgical site vary widely among clinicians and institutions.
Correspondence: Admir Hadzic

The New York School of Regiona Anesthesia (NYSORA),

2753 Broadway, Suite 183,

New York, NY, USA 10025

Emailadmir@nysora.com 
For example, commonly used doses of bupivacaine $\mathrm{HCl}$ range from 50 to $125 \mathrm{mg}$, whereas the reported weight/volume concentrations typically vary between 2.5 and $5.0 \mathrm{mg} / \mathrm{mL} .^{6-10}$ A single vial of liposome bupivacaine contains approximately 740 million liposomes; thus, it is possible that the drug can also be volume-expanded without a negative effect on its analgesic efficacy. As the saline diluent is absorbed, it leaves the liposomes in the tissue as micro-depots that continue to release bupivacaine over time (Figure 1).

A $266 \mathrm{mg} / 20 \mathrm{~mL}$ vial of liposome bupivacaine can be administered with or without dilution. When diluted, the volume of the suspension can be expanded with normal saline solution $(0.9 \%)$ for injection up to a maximum total volume of $300 \mathrm{~mL}(0.89 \mathrm{mg} / \mathrm{mL} ; 0.089 \%)$ as needed to accommodate larger surgical sites. ${ }^{4}$

To evaluate the potential relationship between volume expansion and analgesic efficacy following surgical site infiltration with liposome bupivacaine in humans, we analyzed the data from liposome bupivacaine Phase II and III clinical studies, as well as a post-approval volume expansion study of liposome bupivacaine. Results from a preclinical study specifically designed to assess the impact of volume, dose, and drug concentration on the pharmacokinetics of liposome bupivacaine are also presented.

\section{Clinical efficacy of liposome bupivacaine and the concentration- efficacy relationship}

In 2012, Dasta et $\mathrm{al}^{11}$ reported results from a pooled analysis of nine clinical studies of liposome bupivacaine administered intraoperatively at the surgical site as part of a multimodal

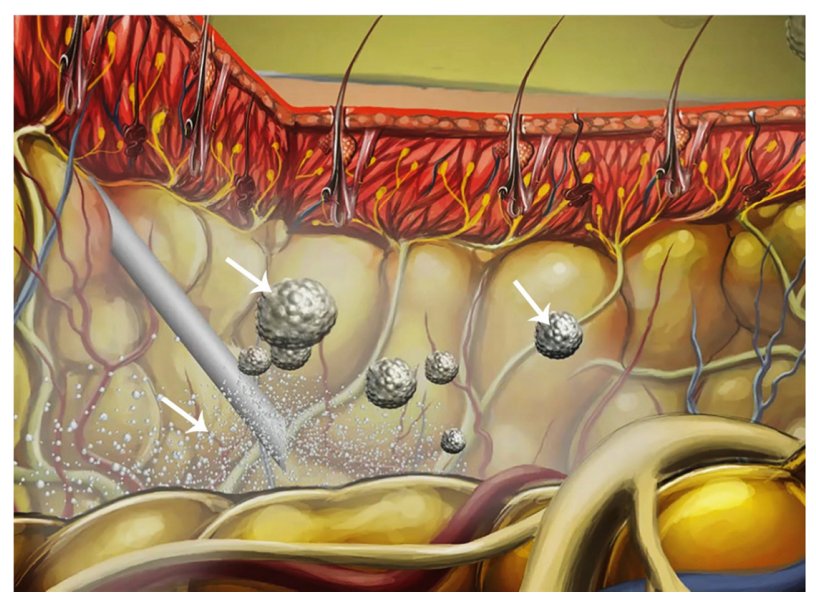

Figure I Schematic image of an injection of liposome bupivacaine into the surgical site. Notes: White arrows point to liposomes; white haze illustrates free bupivacaine contained in liposome bupivacaine solution. Image courtesy of Avenue- $V$ Media, New York, NY, USA. analgesic regimen in patients undergoing inguinal hernia repair, total knee arthroplasty, hemorrhoidectomy, breast augmentation, or bunionectomy $(\mathrm{N}=1,379) .{ }^{11}$ The subjects received liposome bupivacaine in doses ranging from $66 \mathrm{mg}$ to $532 \mathrm{mg}$ (two times the maximum FDA-approved dosage) given with and without dilution in volumes ranging from $8 \mathrm{~mL}$ (bunionectomy [106 $\mathrm{mg} ; 1.33 \%$ ]) to $80 \mathrm{~mL}$ (total knee arthroplasty [532 mg; 0.67\%]), compared with bupivacaine $\mathrm{HCl}$, given at doses ranging from 75 to $200 \mathrm{mg}$, or placebo. ${ }^{11-18}$ The milligram dose of liposome bupivacaine is expressed as the free base (ie, $266 \mathrm{mg}$ of bupivacaine base is chemically equivalent to $300 \mathrm{mg}$ of bupivacaine $\mathrm{HCl}$ ). Pain intensity was measured using an eleven-point numeric rating scale $(\mathrm{NRS})(0=$ no pain; $10=$ worst possible pain $)$ or $100 \mathrm{~mm}$-length visual analog scale $(0=$ no pain; $100=$ most severe pain possible) throughout the 72 -hour study period. Key efficacy outcomes included mean area under the curve (AUC) of NRS pain intensity scores, time to first opioid use, and total amount of opioids consumed postoperatively.

Across studies, the use of liposome bupivacaine $\leq 266 \mathrm{mg}$ was associated with significantly lower mean AUC of pain intensity scores compared with bupivacaine $\mathrm{HCl}$ through 72 hours after surgery ( 283 vs $329 ; P=0.039$ ), a longer median time to first opioid use (9.9 vs 2.7 hours; $P<0.0001$ ), and a lower mean amount of postsurgical opioids consumed after surgery (12 mg vs $19 \mathrm{mg} ; P<0.0001) .{ }^{11}$

We analyzed data in these nine studies to evaluate the effect of volume expansion on efficacy. ${ }^{11-18}$ Subject-reported pain intensity scores at 4 hours post-surgery (the earliest timed assessment used in eight of nine studies) and at 24 hours post-surgery were evaluated. Liposome bupivacaine concentrations varied from a low of $0.22 \%(2.2 \mathrm{mg} / \mathrm{mL})$ to a high of $1.33 \%(13.3 \mathrm{mg} / \mathrm{mL})$. The largest treatment effect associated with liposome bupivacaine was observed in study 4 (hemorrhoidectomy), ${ }^{15}$ where all three dose concentrations of liposome bupivacaine tested were associated with a $\geq 49 \%$ difference in mean pain intensity scores compared with bupivacaine $\mathrm{HCl}$ at 4 hours post-surgery (Table 1). ${ }^{11-18}$ No apparent concentration-efficacy relationship was observed among the studies that utilized different concentrations of liposome bupivacaine in the same surgical procedure. Likewise, no relationship was observed across studies that utilized similar concentrations of liposome bupivacaine in different surgical models. Higher concentrations of liposome bupivacaine were not associated with lower pain intensity, and in some instances, lower concentrations produced greater reductions in pain intensity than higher concentrations (Table 1). 


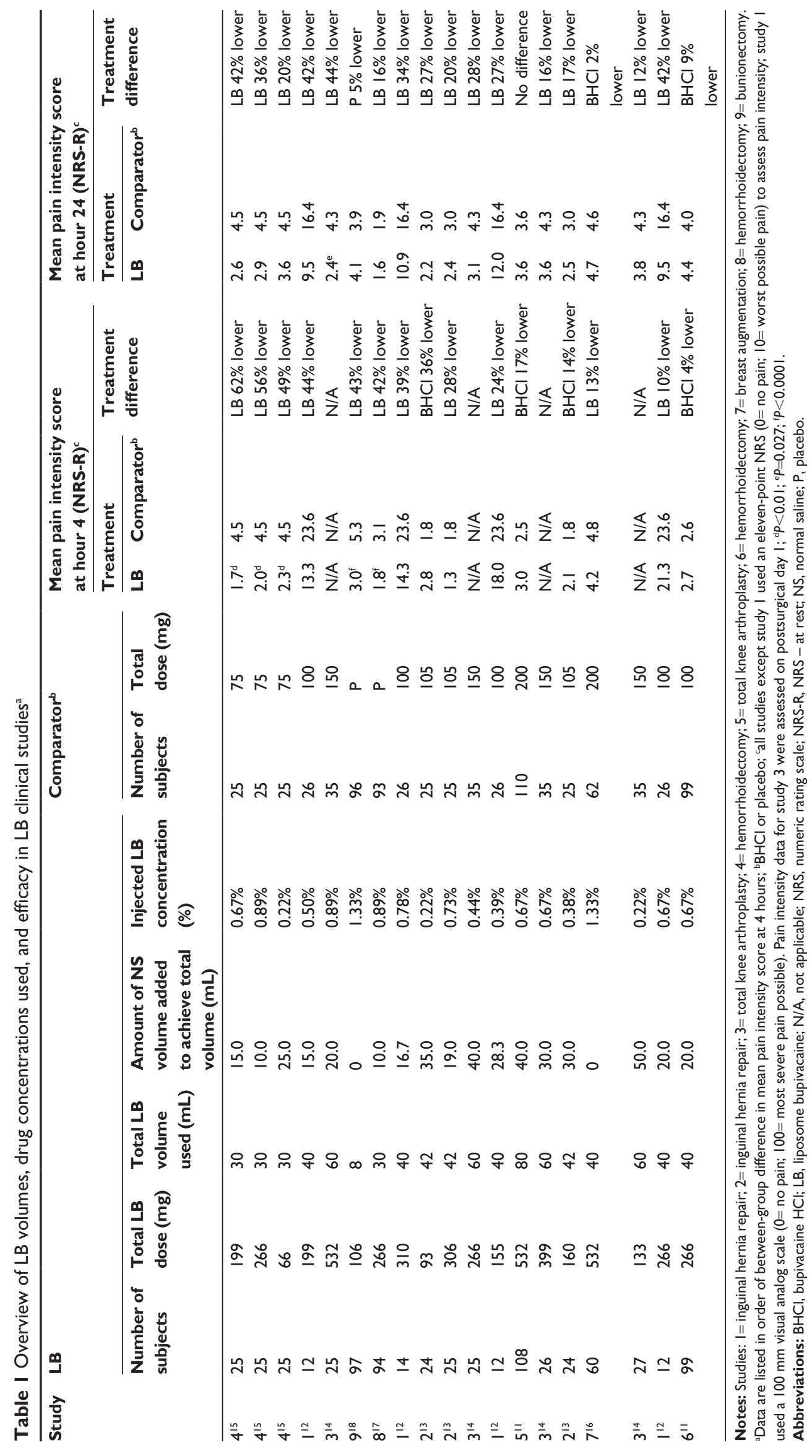


Sternlicht et a ${ }^{19}$ reported results from a prospective study that assessed the efficacy and safety of the same total dose, but two different concentrations/volumes, of liposome bupivacaine given via bilateral transversus abdominis plane infiltration in adult males undergoing robotic-assisted laparoscopic prostatectomy. In this single-center, prospective, open-label, sequential-cohort study, all subjects received $266 \mathrm{mg}$ of liposome bupivacaine. The first 12 subjects received liposome bupivacaine $266 \mathrm{mg}$ in a total volume of $20 \mathrm{~mL}(13.3 \mathrm{mg} / \mathrm{mL}$ [1.33\%]; high-concentration group), and the next 12 subjects received liposome bupivacaine $266 \mathrm{mg}$ in a total volume of $40 \mathrm{~mL}$ (6.7 mg/mL [0.67\%]; low-concentration group). The solution of $\mathrm{NaCl} 0.9 \%$ was used for volume expansion in the second group. Outcome measures included time to first postoperative opioid administration, subject-reported pain intensity assessed through 96 hours after surgery and on postoperative day 10 using an eleven-point $\operatorname{NRS}(0=$ no pain; $10=$ worst possible pain), and total amount (morphine equivalents) of opioids used postoperatively during the hospital stay.

The median (95\% confidence interval $[\mathrm{CI}])$ time to first postoperative opioid administration was 23 (95\% CI: $14-42)$ minutes in the high-concentration group compared with
26 (95\% CI: 11-37) minutes in the low-concentration group. Mean postoperative pain intensity scores were low in both groups ( $\leq 3.0$ at all timed assessments from 6 to 72 hours), and scores were similar in the low- and high-concentration groups at all timed assessments (Figure 2). ${ }^{19}$ The mean (standard deviation) amount of postoperative opioids consumed during hospitalization was similar (25 [9] $\mathrm{mg}$ in the high-concentration group compared with 27 [9] mg in the low-concentration group).

\section{Effects of drug concentration on the pharmacokinetics of liposome bupivacaine in animals}

Plasma bupivacaine concentrations were assessed in Sprague Dawley rats following subcutaneous injections of liposome bupivacaine at various injection volumes, doses, and concentrations (Pacira Pharmaceuticals, Inc., data on file, 2011). Six groups of rats ( $\mathrm{n}=5$ per group) received subcutaneous injections: 1) $0.6 \mathrm{~mL}$ of liposome bupivacaine $2.40 \%$; 2) $0.5 \mathrm{~mL}$ of liposome bupivacaine $1.58 \%$; 3 ) $0.25 \mathrm{~mL}$ of liposome bupivacaine $1.58 \%$; 4) $1 \mathrm{~mL}$ of liposome bupivacaine $1.58 \%$; 5) $1 \mathrm{~mL}$ of liposome bupivacaine $0.84 \%$; or 6 ) four injections of $0.25 \mathrm{~mL}$ of liposome bupivacaine $0.84 \%$. Blood

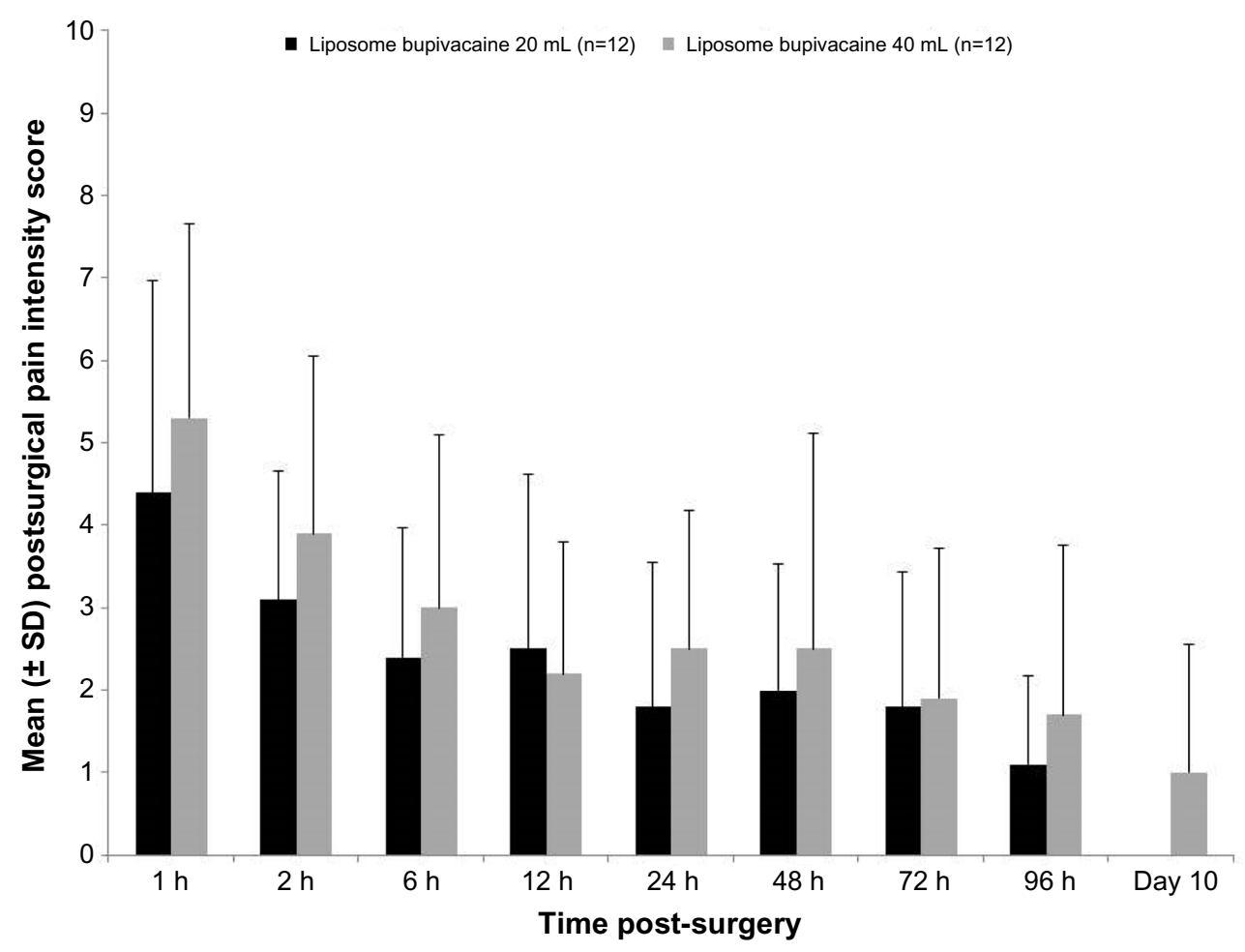

Figure 2 Mean $( \pm S D)$ subject-reported pain intensity scores assessed using a numeric rating scale $(0=$ no pain; $10=$ worst possible pain) in adult males who received liposome bupivacaine $266 \mathrm{mg} / 20 \mathrm{~mL}$ ( $13.3 \mathrm{mg} / \mathrm{mL}$ [1.33\%]; $\mathrm{n}=12)$ or liposome bupivacaine $266 \mathrm{mg} / 40 \mathrm{~mL}(6.7 \mathrm{mg} / \mathrm{mL}$ [0.67\%]; $\mathrm{n}=12)$ via bilateral transversus abdominis plane infiltration for postsurgical analgesia following robotic-assisted laparoscopic prostatectomy.

Notes: Republished with permission of Sternlicht A, Shapiro M, Robelen G, Vellayappan U, Tuerk IA. Infiltration of liposome bupivacaine into the transversus abdominis plane for postsurgical analgesia in robotic laparoscopic prostatectomy: a pilot study. Local Reg Anesth. 20I4;7:69-74. ${ }^{19}$ Copyright (C) 20I4. Permission conveyed through Copyright Clearance Center, Inc.

Abbreviations: h, hours; SD, standard deviation. 
samples for pharmacokinetic analysis were obtained prior to injection and at $0.5,1,2,6,24,48,72$, and 96 hours after study drug administration.

Despite the differences in administered doses and concentrations of liposome bupivacaine, pharmacokinetics were similar among the treatment groups (Table 2) (Pacira Pharmaceuticals, Inc., data on file, 2011). This is also illustrated by the plasma bupivacaine concentration-vs-time profiles for groups 2 and 5 (Figure 3) (Pacira Pharmaceuticals, Inc., data on file, 2011). Animals in these groups were administered approximately the same dose of liposome bupivacaine $(\approx 23 \mathrm{mg} / \mathrm{kg})$, but in different concentrations: $1.58 \%$ in group 2 vs $0.84 \%$ in group 5. However, the resulting plasma bupivacaine concentration curves were nearly identical, indicating that the difference in drug concentration or effect of dilution did not impact the pharmacokinetic profile of liposome bupivacaine.

\section{Discussion}

The maximum FDA-approved dose of liposome bupivacaine is $266 \mathrm{mg}$ supplied in a $20 \mathrm{~mL}$ vial. However, larger volumes of this dose may be necessary to cover surgical areas adequately, and the available clinical studies suggest that the analgesic effect of liposome bupivacaine may not be affected by volume expansion. ${ }^{11-18}$ A preclinical pharmacokinetic study has also demonstrated that volume expansion of liposome bupivacaine does not have a meaningful effect on its pharmacokinetic profile. Thus, it appears that liposome bupivacaine can be used at the concentration supplied by the manufacturer $(1.33 \%)^{4}$ for coverage of a small surgical area (eg, bunionectomy) or expanded up to $300 \mathrm{~mL}$ total volume $(0.089 \%)$ for infiltration of a larger surgical site. Future studies are therefore indicated to determine the minimal effective dose for surgical site infiltration for specific surgical procedures.

A possible explanation for the apparent lack of relationship between liposome bupivacaine concentration and analgesic efficacy may be that the lowest dosages of liposome bupiva- caine tested in the clinical studies outlined earlier achieved a minimum threshold of bupivacaine exposure in the local tissues where the drug was administered. The liposome bupivacaine concentrations used in all of the clinical studies were $\geq 2.5$ times higher than the minimum concentration $(0.89 \mathrm{mg} / \mathrm{mL}$ [0.089\%]) recommended in the prescribing information for the drug. ${ }^{4}$ Thus, there may be a ceiling effect when all nociceptors in surrounding tissues are exposed to the minimum level of local anesthetic needed to produce analgesia. The minimum threshold may depend on a number of factors, including whether the mass of drug around local tissue nociceptors reaches the threshold needed to inhibit depolarization.

Existing clinical and pharmacokinetic data (Pacira Pharmaceuticals, Inc., data on file, 2011) $)^{11-18}$ suggest that the prolonged analgesic efficacy associated with liposome bupivacaine may be related to the ability of FDA-approved doses to achieve and maintain the minimum threshold level of bupivacaine needed at local tissues for adequate analgesia. Quick absorption of the diluent by tissues surrounding the area of administration leaves the liposomes embedded in tissues where the drug is placed.

Our observations regarding the analgesic efficacy data included in this review should be interpreted within the context of the specific limitations associated with the design and setting for each of the individual studies. The analgesic efficacy observed in a controlled study conducted in a specific surgical setting that includes a well-defined patient population who are given study drug via a standardized technique may not be reflective of results that might be observed with the same study drug when administered in other surgical models, in different patient populations, by other modes of administration or with inappropriate administration techniques, or in uncontrolled "real-world" clinical settings. Furthermore, it should be recognized that all pain studies are inherently limited by the subjective nature and variability in pain perception across individuals. Additional studies are needed regarding the safety and efficacy of this prolonged-release formulation

Table 2 Pharmacokinetic parameters of liposome bupivacaine following subcutaneous injection in rats (Pacira Pharmaceuticals, Inc., data on file, $201 \mathrm{I})^{\mathrm{a}, \mathrm{b}}$

\begin{tabular}{llllllll}
\hline Group & Rat wt $(\mathbf{g})$ & Dose $(\mathbf{m g} / \mathbf{k g})$ & $\mathbf{C}_{\max }(\mu \mathrm{g} / \mathbf{m L})$ & $\mathbf{t}_{\max }(\mathbf{h})$ & AUC $_{0-48}(\mu \mathrm{g} \cdot \mathbf{h} / \mathbf{m L})$ & AUC $_{\text {last }}(\mu \mathrm{g} \cdot \mathbf{h} / \mathbf{m L})$ & $\mathbf{A U C} / \mathbf{d o s e}(\mathrm{g} \cdot \mathbf{h} / \mathbf{m L})$ \\
\hline $\mathrm{I}$ & 354.0 & 40.7 & $0.268 \pm 0.078$ & $2-48$ & $8.824 \pm 1.400$ & $11.800 \pm 2.177$ & $0.290 \pm 0.054$ \\
2 & 353.4 & 22.4 & $0.145 \pm 0.04 \mathrm{I}$ & $2-6$ & $4.956 \pm 0.720$ & $5.991 \pm 0.563$ & $0.268 \pm 0.025$ \\
3 & 357.0 & 11.1 & $0.097 \pm 0.044$ & $\mathrm{I}-2$ & $2.084 \pm 0.46 \mathrm{I}$ & $2.686 \pm 0.879$ & $0.241 \pm 0.082$ \\
4 & 354.8 & 44.5 & $0.339 \pm 0.105$ & $\mathrm{I}-48$ & $8.739 \pm 0.934$ & $10.485 \pm 1.125$ & $0.235 \pm 0.025$ \\
5 & 354.4 & 23.7 & $0.162 \pm 0.036$ & $\mathrm{I}-6$ & $4.565 \pm 0.5 \mathrm{II}$ & $5.247 \pm 0.508$ & $0.221 \pm 0.021$ \\
6 & 355.2 & 23.6 & $0.359 \pm 0.239$ & $\mathrm{I}-6$ & $5.197 \pm 1.785$ & $5.724 \pm 2.114$ & $0.242 \pm 0.089$ \\
\hline
\end{tabular}

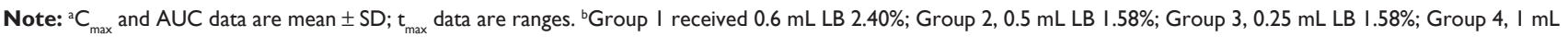
LB I.58\%; Group 5, I mL LB 0.84\%; and Group 6, 4 injections of $0.25 \mathrm{~mL}$ LB $0.84 \%$.

Abbreviations: $A \cup C$, area under the plasma concentration-time curve; $A \cup C_{0-48}$, $A \cup C$ from time zero to 48 hours; $A \cup C_{\text {last' }} A \cup C$ from time zero to the last measurable concentration; $\mathrm{C}_{\max }$, maximum plasma concentration; $\mathrm{h}$, hours; $\mathrm{LB}$, liposome bupivacaine; $\mathrm{t}_{\max }$, time to $\mathrm{C}_{\max }$; wt, weight. 


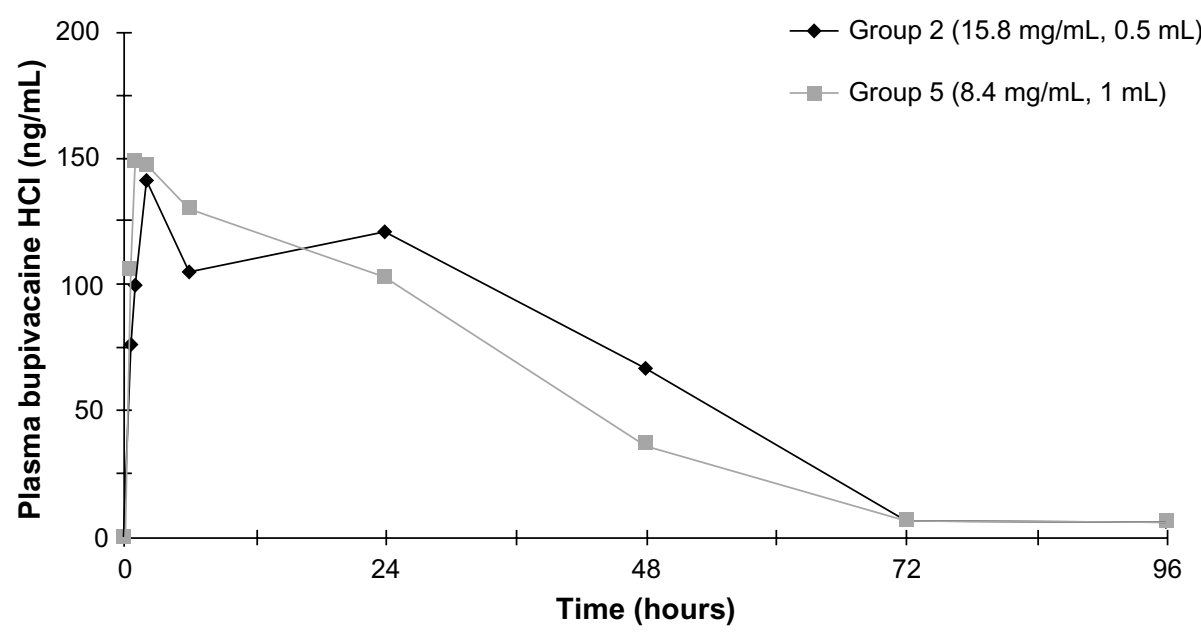

Figure 3 Mean plasma bupivacaine $\mathrm{HCl}$ concentration over time following subcutaneous administration of high- versus low-density liposome bupivacaine in rats (Pacira Pharmaceuticals, Inc., data on file, 20II).

when administered into the surgical site in a more diverse array of surgical settings and patient populations.

\section{Conclusion}

Based on available data, volume expansion of liposome bupivacaine $266 \mathrm{mg}$ (up to a total volume of $300 \mathrm{~mL}$ ) does not appear to affect its clinical efficacy or pharmacokinetic profile.

\section{Acknowledgments}

Editorial assistance was provided by Peloton Advantage, LLC, supported by Pacira Pharmaceuticals, Inc. Statistical review was provided by James Nezamis of Pacira Pharmaceuticals, Inc. The authors were fully responsible for the content, editorial decisions, and opinions expressed in the current article. The authors did not receive an honorarium related to the development of this paper.

\section{Disclosure}

Admir Hadzic, MD, PhD, is a consultant for Pacira Pharmaceuticals, Inc. He receives royalty income from B. Braun Medical, Inc., and has received research funding from GlaxoSmithKline plc, Pacira Pharmaceuticals, Inc., and Baxter International Inc. William J Harmon, MD, is a consultant and speaker for and stockholder of Pacira Pharmaceuticals, Inc. He is not an employee of Pacira Pharmaceuticals, Inc. The authors report no other conflicts of interest in this work.

\section{References}

1. American Society of Anesthesiologists Task Force on Acute Pain Management. Practice guidelines for acute pain management in the perioperative setting: an updated report by the American Society of Anesthesiologists Task Force on Acute Pain Management. Anesthesiology. 2012;116(2):248-273.
2. Ilfeld BM. Continuous peripheral nerve blocks: a review of the published evidence. Anesth Analg. 2011;113(4):904-925.

3. Covino BG, Wildsmith JAW. Clinical pharmacology of local anesthetic agents. In: Cousins MJ, Bridenbaugh PO, editors. Neural Blockade in Clinical Anesthesia and Management of Pain. 3rd ed. Philadelphia: Lippincott-Raven; 1998:97-128.

4. Expare ${ }^{\circledR}$ (bupivacaine liposome injectable suspension) [prescribing information]. Parsippany, NJ: Pacira Pharmaceuticals, Inc.; 2014.

5. Chahar P, Cummings KC 3rd. Liposomal bupivacaine: a review of a new bupivacaine formulation. J Pain Res. 2012;5:257-264.

6. Nesioonpour Sh, Akhondzadeh R, Pipelzadeh MR, Rezaee S, Nazaree E, Soleymani M. The effect of preemptive analgesia with bupivacaine on postoperative pain of inguinal hernia repair under spinal anesthesia: a randomized clinical trial. Hernia. 2013;17(4):465-470.

7. Elliott S, Eckersall S, Fligelstone L, Jothilingam S. Does the addition of clonidine affect duration of analgesia of bupivacaine wound infiltration in inguinal hernia surgery? Br J Anaesth. 1997;79(4):446-449.

8. Lau H, Patil NG, Lee F, Yuen WK. A prospective trial of analgesia following endoscopic totally extraperitoneal (TEP) inguinal hernioplasty. Surg Endosc. 2002;16(1):159-162.

9. Bay-Nielsen M, Klarskov B, Bech K, Andersen J, Kehlet H. Levobupivacaine vs bupivacaine as infiltration anaesthesia in inguinal herniorrhaphy. Br J Anaesth. 1999;82(2):280-282.

10. Dierking GW, Ostergaard E, Ostergård HT, Dahl JB. The effects of wound infiltration with bupivacaine versus saline on postoperative pain and opioid requirements after herniorrhaphy. Acta Anaesthesiol Scand. 1994;38(3):289-292.

11. Dasta J, Ramamoorthy S, Patou G, Sinatra R. Bupivacaine liposome injectable suspension compared with bupivacaine $\mathrm{HCl}$ for the reduction of opioid burden in the postsurgical setting. Curr Med Res Opin. 2012; 28(10):1609-1615.

12. Langford RM, Chappell GM, Karrasch JA. A single administration of DepoBupivacaine intraoperatively results in prolonged detectable plasma bupivacaine and analgesia in patients undergoing inguinal hernia repair. Abstract P-9088. Presented at: Annual Postgraduate Assembly in Anesthesiology of the New York State Society of Anesthesiologists; December 12-16, 2008; New York, NY.

13. White PF, Schooley GL, Ardeleanu M. Analgesia following a single administration of depobupivacaine intraoperatively in patients undergoing inguinal herniorrhaphy: preliminary dose-ranging studies [abstract S-242]. Anesth Analg. 2009;108 Suppl 3S:S-242. Available from: http://www.iars.org/assets/1/7/2009_Abstract_Supplement.pdf

14. Bramlett K, Onel E, Viscusi ER, Jones K. A randomized, double-blind, doseranging study comparing wound infiltration of DepoFoam bupivacaine, an extended-release liposomal bupivacaine, to bupivacaine $\mathrm{HCl}$ for postsurgical analgesia in total knee arthroplasty. Knee. 2012;19(5):530-536. 
15. Haas E, Onel E, Miller H, Ragupathi M, White PF. A double-blind, randomized, active-controlled study for post-hemorrhoidectomy pain management with liposome bupivacaine, a novel local analgesic formulation. Am Surg. 2012;78(5):574-581.

16. Smoot JD, Bergese SD, Onel E, Williams HT, Hedden W. The efficacy and safety of DepoFoam bupivacaine in patients undergoing bilateral, cosmetic, submuscular augmentation mammoplasty: a randomized, double-blind, active-control study. Aesthet Surg J. 2012;32(1):69-76.

17. Gorfine SR, Onel E, Patou G, Krivokapic ZV. Bupivacaine extendedrelease liposome injection for prolonged postsurgical analgesia in patients undergoing hemorrhoidectomy: a multicenter, randomized, double-blind, placebo-controlled trial. Dis Colon Rectum. 2011;54(12):1552-1559.
18. Golf M, Daniels SE, Onel E. A phase 3, randomized, placebo-controlled trial of DepoFoam ${ }^{\circledR}$ bupivacaine (extended-release bupivacaine local analgesic) in bunionectomy. Adv Ther. 2011;28(9):776-788.

19. Sternlicht A, Shapiro M, Robelen G, Vellayappan U, Tuerk IA. Infiltration of liposome bupivacaine into the transversus abdominis plane for postsurgical analgesia in robotic laparoscopic prostatectomy: a pilot study. Local Reg Anesth. 2014;7:69-74.

\section{Publish your work in this journal}

Local and Regional Anesthesia is an international, peer-reviewed, open access journal publishing on the development, pharmacology, delivery and targeting and clinical use of local and regional anesthetics and analgesics. The journal welcomes submitted papers covering original research, basic science, clinical studies, reviews \& evaluations,

\section{Dovepress}

guidelines, expert opinion and commentary, case reports and extended reports. The manuscript management system is completely online and includes a very quick and fair peer-review system, which is all easy to use. Visit http://www.dovepress.com/testimonials.php to read real quotes from published authors.

Submit your manuscript here: http://www.dovepress.com/local-and-regional-anesthesia-journal 